\title{
Recombinant antigens r-PROE and r-IGLL1 for serodiagnosis of feather duvet lung
}

\author{
Adeline Rouzet ${ }^{1}$, Ferran Morell ${ }^{2}$, Gabriel REBOUX ${ }^{3}$, Ana Villar ${ }^{2}$, Laurence Millon ${ }^{4}$, and \\ Maria-Jesús Cruz ${ }^{5}$ \\ ${ }^{1}$ University Hospital Centre Besancon \\ ${ }^{2}$ Hospital Vall d'Hebron \\ ${ }^{3}$ UMR/CNRS 6249 Chrono Environnement University Hospital J. Minjoz \\ ${ }^{4} \mathrm{CHU}$ Besancon \\ ${ }^{5} \mathrm{VHUH}$
}

September 24, 2020

\begin{abstract}
Background: Feather duvet lung (FDL) is an underestimated form of acute and chronic hypersensitivity pneumonitis. Serological tests for FDL need to be validated. We investigated the ability of recombinant pigeon Proproteinase E (r-PROE) and Immunoglobulin-lambda-like-polypeptide-1 (r-IGLL1) proteins to support the serological diagnosis of FDL, and propose them as a serological tool for clinicians to differentiate cases from FDL and Bird fancier's lung (BFL). Methods: Specific IgG antibodies against r-PROE and r-IGLL1, analyzed with ELISA, were measured in patients diagnosed with FDL ( $\mathrm{n=31}$ ), BFL $(n=15)$ controls exposed $(n=15)$ and unexposed to feathers $(n=15)$. Results: The sensitivity and specificity of the r-PROE ELISA for the serological diagnosis of FDL cases versus exposed and unexposed controls were $74.2 \%$ and $86.7 \%$ respectively, with an index threshold of 0.5. (AUC: 0.9). In addition, this serological test was effective to support the serological diagnosis of FDL and BFL cases with significantly different thresholds. The r-IGLL1 ELISA was only effective for the serological diagnosis of BFL. Also, these two serological tests were useful for the diagnosis of both chronic and acute forms. Conclusions: The new diagnostic test for FDL using r-PROE protein should help to detect overt and hidden cases of FDL. The combination of both test will help the clinician in distinguish between the etiology of birds or feathers duvet.
\end{abstract}

\section{ABSTRACT}

Background : Feather duvet lung (FDL) is an underestimated form of acute and chronic hypersensitivity pneumonitis. Serological tests for FDL need to be validated. We investigated the ability of recombinant pigeon Proproteinase E (r-PROE) and Immunoglobulin-lambda-like-polypeptide-1 (r-IGLL1) proteins to support the serological diagnosis of FDL, and propose them as a serological tool for clinicians to differentiate cases from FDL and Bird fancier's lung (BFL).

Methods: Specific IgG antibodies against r-PROE and r-IGLL1, analyzed with ELISA, were measured in patients diagnosed with FDL $(\mathrm{n}=31)$, BFL $(\mathrm{n}=15)$ controls exposed $(\mathrm{n}=15)$ and unexposed to feathers $(\mathrm{n}=15)$.

Results: The sensitivity and specificity of the r-PROE ELISA for the serological diagnosis of FDL cases versus exposed and unexposed controls were $74.2 \%$ and $86.7 \%$ respectively, with an index threshold of 0.5 . (AUC: 0.9 ). In addition, this serological test was effective to support the serological diagnosis of FDL and BFL cases with significantly different thresholds. The r-IGLL1 ELISA was only effective for the serological diagnosis of BFL. Also, these two serological tests were useful for the diagnosis of both chronic and acute forms. 
Conclusions: The new diagnostic test for FDL using r-PROE protein should help to detect overt and hidden cases of FDL. The combination of both test will help the clinician in distinguish between the etiology of birds or feathers duvet.

KEY WORDS : Diagnosis, ELISA, Hypersensitivity pneumonitis, Pillow, Specific IgG antibodies

\section{Introduction}

Hypersensitivity pneumonitis (HP) is an inflammatory and/or fibrotic diffuse parenchymal lung disease, arising in susceptible individuals after repeated and prolonged inhalation to specific antigens ${ }^{1}$. The inciting antigens are most often derived from bacteria, fungi, animal, and plant (glyco) proteins, low molecular-weight chemicals, and metals ${ }^{2}$. The diagnosis of HP is challenging given its heterogeneous clinical presentation and overlapping features with many other forms of interstitial lung disease. In general, its diagnosis is based on a combination of clinical, radiological, histological, and biological features ${ }^{1,3,4}$.

One of the most common forms of HP is bird-fancier's lung (BFL), caused by exposure to wild or domestic birds ${ }^{5}$. Antigen sources are bird droppings, feathers and bloom (a waxy powder that coats the feathers) ${ }^{6}$. However, exposure to feather/down proteins hidden in commonly used objects is involved in another group of avian HP called feather duvet lung (FDL). Feather pillows and down duvets are the main antigenic sources due to their proximity to the respiratory tract and long duration of daily exposure. An increase in the use of goose and duck down in bedding, decorative pillows, clothing and stuffed furniture has been observed in recent years ${ }^{7}$. Exposure to feathers from bedding has been assessed at $30 \%$ of the population in Catalonia ${ }^{8}$ and France (personal data). In Catalonia, the prevalence of FDL for a period of 10 years has been estimated at 6.2 / 100,000 users of feather bedding compared to a prevalence of 54.6 / 100,000 among bird breeders ${ }^{8}$. FDL is characterized as an under-recognized and consequently underestimated form of HP in several studies ${ }^{7,9,10}$. In some cases, if not diagnosed early enough, the disease can progress to irreversible pulmonary fibrosis, leading to permanent damage and the premature death of the patient ${ }^{2}$.

A recent modified Delphi survey on chronic HP shows that exposure to a causative antigen is the most important clinical variable supporting a confident diagnosis ${ }^{3}$. Although the use of serological tests is not universally accepted, they can be used to demonstrate antigenic exposure by looking for circulating precipitins or IgG antibodies ${ }^{3}, 11,12$.

The antigens routinely used in the diagnosis of FDL are purified mixtures of goose or duck feather whose performance varies from one batch to another. The identity of the antigens involved in FDL is currently unknown. Recent studies have characterized two pigeon proteins called immunoglobulin-lambdalike-polypeptide-1 (IGLL1) and proproteinase E (PROE) ${ }^{13}$, which are useful for the serological diagnosis of $\mathrm{BFL}^{13,14}$.

The IGLL1 protein has been identified in droppings, bloom, and pigeon serum and PROE protein in droppings and bloom. A strong correlation has been shown between the IgG antibody response of patients sensitized to pigeon, duck and goose antigens ${ }^{11}$. Therefore, we hypothesize that amino-acid sequences close to those found in IGLL1 and PROE are part of proteins from the feathers (goose, duck) used for the manufacture of pillows and duvets.

This study aimed (i) to assess the performance characteristic of r-IGLL1 and r-PROE (ii) to support the serological diagnosis of FDL, compare the level of sensitization of FDL and BFL patients and (iii) to provide an effective and useful tool for clinicians to guide the diagnosis of HP of avian origin.

\section{METHODS}

\section{Study design}

This study comprised patients diagnosed with FDL, BFL and controls exposed or unexposed to feathers without HP. The 31 FDL patients were recruited in the Pneumology Unit at the Hospital Universitari Vall d'Hebron (Barcelona, Catalonia, Spain). The 15 BFL patients and the 30 controls were recruited by the University hospital of Besancon (France). The patients who are included in the study have given their 
informed consent. The FDL and BFL patients had a confident diagnosis of HP according to the criteria reported below. Blood collection was performed for each patients and controls at the time of diagnosis and kept frozen to $-80^{\circ} \mathrm{C}$ until their analysis.

\section{Hospital Universitari Vall d'Hébron (Barcelona, Catalonia, Spain)}

The criteria used to diagnose HP were those defined by Vasakova et al. ${ }^{12}$. FDL patients $(\mathrm{n}=31)$ were selected from an ongoing prospective study undertaken to evaluate the exposure of environmental factors as potential causative factor/s for new onset interstitial lung disease (ILD). Patients were followed up long-term over the study period from January 2004 to December 2013. The diagnosis of FDL was done according to the following main criteria: (i) no exposure to birds or other environmental factors that could induce HP, (ii) Past or present exposure to feathers hidden in the environment. These last two criteria were assessed using a standardized questionnaire $^{15}$, (iii) Positive specific inhalation challenge and/or specific IgG in the serum. The following antigenic panels were used to measure serum IgG levels by ELISA: bird feathers, bird serum (goose, pigeon, parrot, parakeet, canary), goose feathers and fungus (Aspergillus, Penicillium, Mucor). These patients were included in a previous study (Ethical Committee number: PR(AG) 165/2016), for more clinical details see reference 8 .

\section{Besançon University Hospital (France)}

All BFL patients $(n=15)$ were given a diagnosis between September 2010 to January 2016 according to the following criteria $^{16}$ : (i) A well-known bird exposure (detailed questionnaire, positive precipitin serological test using crude antigens from bird droppings in relation to patient exposure, (ii) No past or present exposure to feathers or other environments involved in HP, (iii) Symptoms and High-resolution computed tomography (HRCT) compatibles with HP and basal crepitant rales, (iv) Bronchoalveolar lavage (BAL) lymphocytosis and (v) Decreased DLCO during exercise. This protocol of recruitment was approved by the local ethics committee (CPP-Est II 15/496). These 15 patients were selected according to their availability in serum from a cohort previously described ${ }^{13}$.

The control groups included 30 patients without HP. They were selected according to their exposure and classified into the following two groups:

- 15 subjects exposed to feather bedding ( $\ll$ Expo feathers $\gg$ ), but not exposed to birds or other environment at risk of HP at the time of diagnosis. They have already been sensitized (i.e., immune system already stimulated by antigen) to avian antigens from feathers but have not developed HP.

- 15 subjects not exposed to feather bedding (« Unexposed »), birds or any environment involved in HP at the time of diagnosis or in the past.

- Measuring of serum specific circulating IgG antibodies against r-PROE and r-IGLL1

Indirect ELISAs using r-PROE and r-IGLL1 were performed in April 2019, in the Parasitology-Mycology department as described by Rouzet et al. ${ }^{13}$. All analyses were performed on the same day for all patients, i.e. retrospectively to the diagnosis. ELISAs were performed without knowing the clinical status of the sera from the Vall d'Hebron department.

Briefly, the wells of 96 -well plates (PolysorpImmunomodule, Nalge Nunc ${ }^{\circledR}$, Rochester, UK) were coated by incubation with $100 \mu \mathrm{L}$ of $10 \mu \mathrm{g} / \mathrm{mL}$ r-PROE and $5 \mu \mathrm{g} / \mathrm{mL}$ r-IGLL1 in phosphate-buffered saline (SigmaAldrich ${ }^{\circledR}$, St Louis, USA) at $4^{\circ} \mathrm{C}$ overnight. Serum samples were diluted $1 / 100$ in dilution buffer, $100 \mu \mathrm{L}$ deposited in triplicate into the wells, and the plates incubated for $1 \mathrm{~h}$ at $37^{\circ} \mathrm{C}$. Polyclonal rabbit antibodies (anti-IGLL1-PROE) (RD-Biotech ${ }^{\circledR}$, Besançon, France) were used as a positive control of the test $(1.8 \mu \mathrm{g} / \mathrm{mL})$ and as a reference sample $(0.4 \mu \mathrm{g} / \mathrm{mL})$. The three optical density values (OD) were blank-corrected and averaged and the standard deviation and variation coefficient calculated. If the coefficient of variation of the triplicate was greater than $20 \%$, the outlier was removed. The ELISAs were carried out twice. An index was calculated as follows: Index $=$ mean OD of the blank-corrected sample replicates/mean OD of the blank-corrected reference sample.

\section{Statistical analysis}


All statistical analyses were performed with R 3.5.3 software and a p-value of 0.05 was used to define statistical significance. Receiver-operator characteristics (ROC) analysis (pROC-package) was performed to evaluate the ability of r-PROE and r-IGLL1 in ELISA to discriminate between Patients with FDL (status $=1$ ) and controls (exposed and unexposed to feathers, status $=0$ ). Therefore, BFL patients have been removed from ROC analysis to avoid overestimation of the performance of these 2 recombinant proteins. The performance of r-PROE and r-IGLL1 was also evaluated to detect the threshold discriminating cases of BFL (status=1) and FDL (status=0). The normality assumption for continuous variables was tested using the multivariate Shapiro-Wilks test; the data were not normally distributed. The nonparametric KruskalWallis $(\mathrm{K})$ test was used to compare the median values between the 4 following groups: FDL, BFL, Expo feathers and Unexposed to feathers. Following a significant $\mathrm{K}$ test, a multiple comparison post hoc test $\left(\mathrm{K}_{\mathrm{MC}}\right)$ using the kruskalmc function ("pgirmess" package) was performed to make inter-group comparisons.

\section{RESULTS}

\subsection{Clinical feature}

Clinical data were obtained from patients' records and have been reported in Table 1. The mean age was 55.2 (26-83) years for the 31 FDL patients (16 women and 15 men) and 64.6 (46-82) years for the 15 BFL patients (10 women, 5 men). Thirty-three per cent of FDL patients were non-smokers compared to $73 \%$ for BFL patients. The antigenic source was a feather duvet for eighteen patients, a feather pillow for five and a combination of both in eight. Over sixty-six percent of BFL patients were exposed to pigeons, and only $20 \%$ were exposed to more than one species of bird. No FDL patients were exposed to birds and no BFL patients were exposed to bedding feathers. Of the patients with FDL, $64.5 \%$ had a chronic course of HP against $40 \%$ for BFL patients. Cough and dyspnea were the predominant symptoms in the two groups of patients. BAL was performed for 28/31 (90\%) patients with FDL and 12/15 (80\%) of BFL patients. A BAL lymphocyte count of at least $20 \%$ were found in 13/28 (46\%) patients FDL and in 12/12 (100\%) of BFL patients.

\subsection{Performance of ELISA serological tests using r-PROE and r-IGLL1}

The immunization against r-PROE and r-IGLL1 of BFL, FDL patients and control subjects was presented on the boxplots of Figure 1. As shown in Figure 1A, BFL patients (median: 1.24) had significantly higher levels of antibodies to r-PROE than FDL patients (median: 0,66, K-test p-value: $2.2 \times 10^{-5}$ ) as well as controls exposed (median :0.34, K-test p-value: $1 \times 10^{-5}$ ) and unexposed to feathers (median: $0.37, \mathrm{~K}$-test p-value: $\left.1 \times 10^{-5}\right)$.

In addition, FDL patients had significantly higher antibody levels than controls exposed (K-test p-value: 2.1 $\mathrm{x} 10^{-5}$ ) and unexposed to feathers (K-test p-value: $9.8 \times 10^{-5}$ ). On the other hand, as shown in Figure 1B, the level of antibodies to r-IGLL1 was significantly higher in BFL patients (median: 2.36) compared to FDL patients (median: 0.33, K-test p-value: $4.2 \times 10^{-7}$ ), controls exposed (median: 0.19, K-test p-value: $6.7 \mathrm{x}$ $10^{-6}$ ) and unexposed to feathers (median: 0.24 , K-test p-value: $6.7 \times 10^{-6}$ ). However, no-significant difference using kruskalmc between FDL patients and controls unexposed to feathers were found (K-test p-value: 0.06). Consequently, r- IGLL1 was contributive to the diagnosis for the serological diagnosis of patients with BFL but ineffective to support FDL diagnosis.

The characteristics of the r-PROE and r-IGLL1 ELISA (sensitivity, specificity and area under the curve) performed by the ROC curve analysis were presented in Table 2. The ELISA test using r-PROE with an index threshold of 0.5 has shown that $74.2 \%$ of patients diagnosed with FDL have a positive test compared to $86.7 \%$ of controls with a negative test $(\mathrm{AUC}=0.9)$. These proteins were effective for the diagnosis of both chronic and acute forms. Indeed, the r-PROE ELISA test provided a consistent diagnosis for 15/20 patients suffering from chronic FDL and 8/11 patients suffering from acute FDL. The ELISA test based on the use of the r-IGLL1 protein provided a correct result for $6 / 6$ patients with chronic BFL and 8/9 patients with acute BFL.

In the case of exposure to both feather bedding and birds, analyses of the ROC curve showed a significant differential threshold between FDL and BFL cases. If the r-PROE ELISA test index value was between 0.5 
and 1, the interpretation was in favor of FDL, while the "bird" etiology was preferred for an index value greater than 1 (Table 2). In addition, if the bird is the cause of the disease, the index value of the IGLL1ELISA test will be greater than 1.1. Based on these results, we have proposed a key choice to support the diagnosis of HP of avian origin according to the patient's exposure, in Figure 2.

\section{DISCUSSION AND CONCLUSIONS}

The development of tools to improve the diagnosis of HP is a challenge and at the heart of current concerns, as HP experts have highlighted the need for a diagnostic test to measure serum IgG levels with a wellaccepted threshold ${ }^{2}$. In the present study, we showed that an ELISA test using r-PROE allowed effective discrimination between 31 FDL patients and 30 controls. The r-IGLL1 ELISA test was only useful for the serological diagnosis of the 15 BFL patients. These results will serve as a guide for the clinicians in the choice and interpretation of serological tests to be performed according to the type of avian exposure of patients.

HPs are often difficult to diagnose in part because of the difficulty to identify the antigenic source but also because the clinical behavior of these diseases mimics those of other pulmonary diseases. Indeed, despite thorough investigations, the offending HP-antigen was not identified in $25-53 \%$ of $\operatorname{cases}^{17,18}$. The group of Barcelona reported that $43 \%$ of patients initially identified with idiopathic pulmonary fibrosis actually had a chronic form of HP, half of these cases were due to exposure to feather bedding ${ }^{9}$. Thus, exposure to avian feather proteins may be an unrecognized cause of $\mathrm{HP}^{7,19,20}$. The detection of antigen-specific $\operatorname{IgG}$ antibodies is useful to support the diagnosis of HP, as it allows identification of the causal antigen ${ }^{2,12}$. In our experience, serological analyses were mainly used to rule out the diagnosis of HP in favor of other respiratory pathologies ${ }^{21}$, but also to identify the etiologic agent involved in HP. For serological analyses, several methods to determine precipitins (Ouchterlony double diffusion and Immunoelectrophoresis) ${ }^{22}$ or specific IgG antibodies (ELISA and ImmunoCAPß, Uppsala, Sweden) have been used in analytical laboratories ${ }^{23}$.

ELISA was described as being more sensitive than precipitin assays in detecting antibodies to pigeon droppings for BFL serodiagnosis ${ }^{13}, 22$. Currently, the antigens used for the serological diagnosis of FDL are purified (commercial or non-commercial) from goose feathers, duck feathers, a mixture of both, or from those of other bird species (pigeon, parakeet) ${ }^{24,25}$. Several studies have shown significantly high antibody levels in patients using feather duvet and pillow antigens than controls ${ }^{24-26}$. Comparison of the data obtained is difficult due to the different techniques used but also to the lack of standardization of antigen production ${ }^{11}$.

New techniques, such as proteomics coupled with mass spectrometry (LC-MS/MS), now make it possible to characterize proteins associated with the disease. IgG antibodies against r-IGLL1 and r-PROE proteins have been identified as biomarkers of BFL and have been found in droppings, bloom, and pigeon serum using an optimal immunoproteomic approach ${ }^{13,14}$.

The diagnostic performance of an ELISA test for BFL performed with r-IGLL1 and r-PROE gave the best specificity $(100 \%)$ and sensitivity $(84 \%)^{13}$. These proteins are involved in the immune and digestive systems of birds $^{13}$. Several studies have suggested the presence of cross-reactive antigenic reactions between different bird species or different avian matrices, especially for pigeons ${ }^{14,27-29}$. Recently, significant correlations have been found in serological analyses between pigeon, duck, and goose antigens ${ }^{11}$. Based on the BLASTp alignment, our results showed that the amino-acid sequence of duck IGLL has higher identity with goose IGLL (ID: $81 \%$ ) than pigeon IGLL1 (ID: 65\%) (Supplemental data). On the contrary, the amino-acid sequence of duck PROE has higher sequence identity with pigeon PROE (81\%) than with the orthologous protein in geese $(73 \%)$. The conservation of the amino-acid sequences of these proteins is a contributing factor to the antigenic cross-reaction observed in serological analyses ${ }^{14,28}$. In the present study, we evaluated the performance of an ELISA using the pigeon r-IGLL1 and r-PROE proteins to support the serological diagnosis of FDL cases.

We found the ELISA test using r-IGLL1 to be useful to support the diagnosis of BFL patients but not for FDL cases. Conversely, we found significantly higher levels of circulating IgG antibodies against r-PROE in BFL and FDL patients than controls. Indeed, r-PROE was the most effective antigen for discriminating FDL patients from controls exposed and unexposed to feathers. The characteristic performance of the r-PROE ELISA test using an optimal threshold index value was as follow: sensitivity of $74.2 \%$, specificity of $86.7 \%$ 
and AUC of 0.9 .

The antibodies of patients directed against r-IGLL1 and r-PROE are respectively two and seven times significantly higher in BFL patients compared to FDL patients. Although patients were exposed for long periods to their pillows, but with little agitation, the amount of inhalable antigenic protein was probably lower than that inside an aviary (66.6\% of our BFL patients were pigeon breeders). Indeed, in such a location, antigens come from droppings, bloom, and feathers and are frequently suspended by the birds or the breeder during cleaning. Such differences in exposure intensity may explain the higher level of antibodies in BFL patients compared to the FDL observed in our study.

Since the intensity of sensitization is significantly different between BFL and FDL patients against r-PROE in ELISA (r-IGLL1 specific for BFL patients), we proposed a useful key for cases of patients exposed to both feathers and birds. Although r-PROE and r-IGLL1 were both effective for serodiagnosis of BFL cases, to simplify procedures, we recommend that only r-IGLL1 be used for the diagnosis of patients exposed to birds. Likewise, in the event of a suspected FDL case, r-PROE was the only protein to be used for the ELISA test. In case of multi-exposure (feather bedding + birds), an index value for r-PROE between 0.5 and 1 is in favor of the diagnosis of FDL, and above 1, in favor of BFL case.

Several studies have shown that FDL cases are related to childhood exposure to birds, and that contact with pillow feathers is a trigger for sensitization that occurred long before ${ }^{29-31}$. The use of a feather pillow/duvet should be discouraged in cases of BFL because continuous contact with avian antigens can induce disease progression and cause permanent lung damage ${ }^{9,32,33}$.

Finally, as there is no effective treatment to reverse the lung damage caused by the disease, early identification of the antigenic source is necessary. The diagnosis of FDL should be based on a proactive approach to find the antigen source to remove it from the patient's environment ${ }^{21}$.

In conclusion, we recommend the use of r-PROE and r-IGLL1 proteins, respectively, for the serological diagnosis of patients exposed strictly to bedding feathers or birds and presenting with respiratory symptoms. These two ELISA tests allow the diagnosis of both chronic and acute forms of FDL and BFL cases. The ELISA test based on the use of r-PROE showed a sensitivity of $74.2 \%$ and a specificity of $86.7 \%$ for an AUC of 0.9 for FDL patients. The use of recombinant proteins guarantees highly standardized production and optimal inter-batch reproducibility.

The use of the ELISA test reduces the time taken to report results to patients / clinicians to 3 days. This time saving allows the implementation of an early avoidance strategy favorable to the patient's state of health. This serological approach is efficient, standardized, fast, inexpensive and easy to implement.

\section{REFERENCES}

1. Raghu G, Document S, Remy-Jardin M, et al. Diagnosis of Hypersensitivity Pneumonitis in Adults: An Official ATS/JRS/ALAT Clinical Practice Guideline. American Journal of Respiratory and Critical Care Medicine . 2020; (ja)

2. Nogueira R, Melo N, e Bastos HN, et al. Hypersensitivity pneumonitis: Antigen diversity and disease implications. Pulmonology . 2018;

3. Morisset J, Johannson KA, Jones KD, et al. Identification of Diagnostic Criteria for Chronic Hypersensitivity Pneumonitis. An International Modified Delphi Survey. American journal of respiratory and critical care medicine . 2018;197(8):1036-1044.

4. Lacasse Y, Girard M, Cormier Y. Recent Advances in Hypersensitivity PneumonitisRecent Advances in Hypersensitivity Pneumonitis. CHEST Journal . 2012;142(1):208-217.

5. Morell F, Roger A, Reyes L, Cruz MJ, Murio C, Munoz X. Bird fancier's lung: a series of 86 patients. Medicine . 2008;87(2):110-130. 
6. Rodrigo MJ, Benavent MI, Cruz MJ, et al. Detection of specific antibodies to pigeon serum and bloom antigens by enzyme linked immunosorbent assay in pigeon breeder's disease. Occupational and environmental medicine . 2000;57(3):159-164.

7. Jacobs MR, Andrews CP, Ramirez RM, Jacobs RL. Frequency of goose and duck down causation of hypersensitivity pneumonitis within an 80-patient cohort. Annals of Allergy, Asthma \& Immunology . 2019;123(2):201-207.

8. Morell F, Villar A, Ojanguren I, et al. Hypersensitivity Pneumonitis and (Idiopathic) Pulmonary Fibrosis Due to Feather Duvets and Pillows.Archivos de Bronconeumología . 2020;

9. Morell F, Villar A, Montero M-Á, et al. Chronic hypersensitivity pneumonitis in patients diagnosed with idiopathic pulmonary fibrosis: a prospective case-cohort study. The Lancet Respiratory Medicine . 2013;1(9):685-694.

10. Liu-Shiu-Cheong P, Kuo CR, Wilkie SWA, Dempsey O. Feather duvet lung. BMJ Case Reports CP . $2019 ; 12(11)$

11. Raulf M, Joest M, Sander I, et al. Update of reference values for IgG antibodies against typical antigens of hypersensitivity pneumonitis. Allergo Journal International . 2019:1-12.

12. Vasakova M, Morell F, Walsh S, Leslie K, Raghu G. Hypersensitivity Pneumonitis: Perspectives in Diagnosis and Management. American Journal of Respiratory And Critical Care Medicine . 2017;(ja)

13. Rouzet A, Reboux G, Dalphin J-C, et al. An immunoproteomic approach revealed antigenic proteins enhancing serodiagnosis performance of bird fancier's lung. Journal of immunological methods . 2017;450:58.

14. Shirai T, Furusawa H, Furukawa A, et al. Protein antigen of bird-related hypersensitivity pneumonitis in pigeon serum and dropping. Respiratory Research . 2017;18(1):65.

15. Morell F, Ojanguren I, Cruz M-J. Diagnosis of occupational hypersensitivity pneumonitis. Current opinion in allergy and clinical immunology . 2019;19(2):105-110.

16. Dalphin J-C, Gondouin A. Rare Causes and the Spectrum of Hypersensitivity Pneumonitis. Orphan Lung Diseases . Springer; 2015:457-472.

17. Pérez ERF, Swigris JJ, Forssén AV, et al. Identifying an inciting antigen is associated with improved survival in patients with chronic hypersensitivity pneumonitis. CHEST Journal . 2013;144(5):1644-1651.

18. Hanak V, Golbin JM, Ryu JH. Causes and presenting features in 85 consecutive patients with hypersensitivity pneumonitis. Elsevier; 812-816.

19. Inase N, Ohtani Y, Sumi Y, et al. A clinical study of hypersensitivity pneumonitis presumably caused by feather duvets.Annals of Allergy, Asthma \& Immunology . 2006;96(1):98-104.

20. Jordan LE, Guy E. Paediatric feather duvet hypersensitivity pneumonitis. BMJ case reports . 2015;2015:bcr2014207956.

21. Bellanger A-P, Reboux G, Rouzet A, Barrera C, Rocchi S, Millon L. Hypersensitivity pneumonitis: a new strategy for serodiagnosis and environmental surveys. Respiratory Medicine . 2019;

22. Simpson C, Shirodaria PV, Evans JP, Simpson DI, Stanford CF. Comparison of immunodiffusion and enzyme linked immunosorbent assay in the detection of abnormal antibodies in pigeon breeder's disease. Journal of clinical pathology . 1992;45(6):490-493.

23. Rodrigo MJ, Postigo I, Wangensteen O, Guisantes JA, Martínez J. A new application of Streptavidin

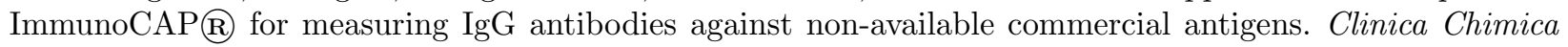
Acta . 2010;411(21):1675-1678. 
24. Koschel D, Lützkendorf L, Wiedemann B, Höffken G. Antigen-specific IgG antibodies in feather duvet lung. European journal of clinical investigation . 2010;40(9):797-802.

25. Sennekamp J, Lehmann E. Improved IgG Antibody Diagnostics of Feather Duvet Lung by an Antibody Screening Test. Pneumologie (Stuttgart, Germany) . 2015;69(11):638-644.

26. Haitjema T, van Velzen-Blad H, Van Den Bosch JM. Extrinsic allergic alveolitis caused by goose feathers in a duvet. Thorax . 1992;47(11):990.

27. Rouzet A, Reboux G, Rognon B, et al. Immunogenic proteins specific to different bird species in bird fancier's lung. Journal of Toxicology and Environmental Health, Part A . 2014;77(12):724-730.

28. Rouzet A, Valot B, Reboux G, Millon L, Roussel S. Common Proteins Located in Pigeon, Budgerigar, and Hen Droppings Related to Bird Fancier's Lung. Journal of investigational allergology \& clinical immunology . 2018;28(3):182.

29. Sterclova M, Vasakova M, Metlicka M. Significance of specific IgG against sensitizing antigens in extrinsic allergic alveolitis: serological methods in EAA. Revista portuguesa de pneumologia . 2011;17(6):253-259.

30. Inase N, Sakashita H, Ohtani Y, et al. Chronic bird fancier's lung presenting with acute exacerbation due to use of a feather duvet.Internal medicine . 2004;43(9):835-837.

31. Shaw J, Leonard C, Chaudhuri N. Feather bedding as a cause of hypersensitivity pneumonitis. QJM: An International Journal of Medicine . 2017;110(4):233-234.

32. Cormier Y. Hypersensitivity pneumonitis (extrinsic allergic alveolitis): A Canadian historical perspective. Canadian respiratory journal: journal of the Canadian Thoracic Society . 2014;21(5):277.

33. Raghu G. Idiopathic pulmonary fibrosis: shifting the concept to irreversible pulmonary fibrosis of many entities. The Lancet Respiratory Medicine . 2019;7(11):926-929.

\section{TABLES}

\begin{tabular}{lll}
\hline & FDL & BFL \\
\hline Number of patients & 31 & 15 \\
Age, mean (SD), years & $55.2(14.5)$ & $64.6(11.6)$ \\
Male sex, n(\%) & $15(48.4)$ & $5(33)$ \\
Tobacco use, n(\%) & & \\
Non-smoker & $10(32.3)$ & $11(73.3)$ \\
Past-smoker & $19(61.3)$ & $4(26.7)$ \\
Active smoker & $2(6.5)$ & 0 \\
Exposure to feather, n(\%) & & \\
Duvet & $18(58.1)$ & 0 \\
Pillow & $5(16.1)$ & 0 \\
Both & $8(25.8)$ & 0 \\
Exposure to birds, n(\%) & & \\
Pigeon & 0 & $10(66.6)$ \\
Parakeet & 0 & $2(13.3)$ \\
Poultry & 0 & $1(6.7)$ \\
Several birds & 0 & $3(20)$ \\
HP classification & & \\
Chronic HP, n(\%) & $20(64.5)$ & $6(40)$ \\
Acute HP , n(\%) & $11(35.5)$ & $9(60)$ \\
Symptoms & & \\
Cought, n(\%) & $31(100)$ & $12(80)$ \\
Dyspnea, n(\%) & $31(100)$ & $14(93.3)$
\end{tabular}




\begin{tabular}{lll}
\hline & FDL & BFL \\
\hline Emphysema, n(\%) & 0 & $1(6.7)$ \\
Crackles, n(\%) & $18(45.5)$ & $10(66.7)$ \\
Analytical data & & \\
BAL-Lymphocytes \%, median (P25-P75) & $12.5(7-36.3)$ & $64(53.8-67.5)$ \\
Pulmonary function tests & & \\
FEV1/FVC (\%pred), mean (SD) & $83.1(5.3)$ & $89.2(16.4)$ \\
DLCO (\% pred), mean (SD) & $50(13.3)$ & $49.3(13.4)$ \\
HRCT & & \\
Ground glass, n(\%) & $15(48.4)$ & $14(93.3)$ \\
Reticular, n(\%) & $4(12.9)$ & $1(6.6)$ \\
Honeycombing, n(\%) & $12(38.7)$ & $4(26.7)$ \\
\hline
\end{tabular}

Table 1: Characteristics and clinical data of 31 patients with FDL and 15 patients with BFL at the time of diagnosis.

Abbreviations : BAL, Bronchoalveolar lavage ; \% pred, percent of predicted value ; FEV1, forced expiratory volume in one second ; FVC, forced vital capacity ; DLCO, diffusing capacity of the lung for carbon monoxide $(\mathrm{CO})$.

\begin{tabular}{llllll}
\hline & $\begin{array}{l}\text { Recombinant } \\
\text { proteins }\end{array}$ & AUC $[95 \% \mathrm{CI}]$ & $\begin{array}{l}\text { Threshold index } \\
\text { value }\end{array}$ & $\begin{array}{l}\text { Sensitivity \% } \\
{[95 \% \mathrm{CI}]}\end{array}$ & $\begin{array}{l}\text { Specificity \% } \\
{[95 \% \mathrm{CI}]}\end{array}$ \\
\hline $\begin{array}{l}\text { ELISA Patients: } \\
\begin{array}{l}\text { FDL vs.controls } \\
\text { (excluding BFL) }\end{array}\end{array}$ & r-PROE & $0.9[0.8-1]$ & 0.5 & $74.2 \%[58.1-90.3]$ & $86.7 \%[73.3-96.7]$ \\
& r-IGLL1 & $0.7[0.61-0.87]$ & 0.26 & $\begin{array}{l}64.5 \% \\
{[48.3-80.6]}\end{array}$ & $83.3 \%[70-96.6]$ \\
$\begin{array}{l}\text { ELISA Patients } \\
\begin{array}{l}\text { BFL vs. FDL } \\
\text { (excluding }\end{array}\end{array}$ & r-PROE & $0.9[0.8-0.98]$ & 1 & $80 \%[60-93.5]$ & $93.5 \%[83.9-100]$ \\
controls) & & & & & \\
& r-IGLL1 & $1[0.98-1]$ & 1.1 & $93.3 \%[80-100]$ & $100 \%[100-100]$ \\
\hline
\end{tabular}

Table 2. Sensitivity, specificity, and ROC values for ELISA results with r-PROE (Proproteinase E) and r-IGLL1 (Immunoglobulin lambda-like polypeptide-1) as antigens.

ROC analyses were performed to compare the index values of r-PROE and r-IGLL1 between patients with FDL and controls. BFL patients were removed to perform this analysis to avoid overestimation of the performance of these recombinant proteins. ROC analyses were also performed between FDL and BFL cases by removing controls, in order to highlight a threshold discriminating the cases of FDL and BFL

\section{FIGURES LEGENDS}

Figure 1. Boxplots of the index values for the r-PROE (A) and r-IGLL1 (B) ELISAs for the different patient groups: FDL $(\mathrm{n}=31)$, BFL $(\mathrm{n}=15)$, Expo feathers $(\mathrm{n}=15)$, Unexposed to feathers $(\mathrm{n}=15)$. For FDL and BFL patients, patients with chronic forms are marked by grey circles and those with acute forms by white circles. The horizontal dotted lines represent the threshold determined by the pROC analysis (highest AUC value) for the r-PROE (0.5) and r-IGLL1 (0.3) ELISAs. The letters (a, b, c) common to several groups indicate no significant difference between the groups (kruskalmc test).

Figure 2. Keys to determining the choice of serological tests for patients with symptoms compatible with 
HP and avian exposure.

\section{FIGURE FILES}
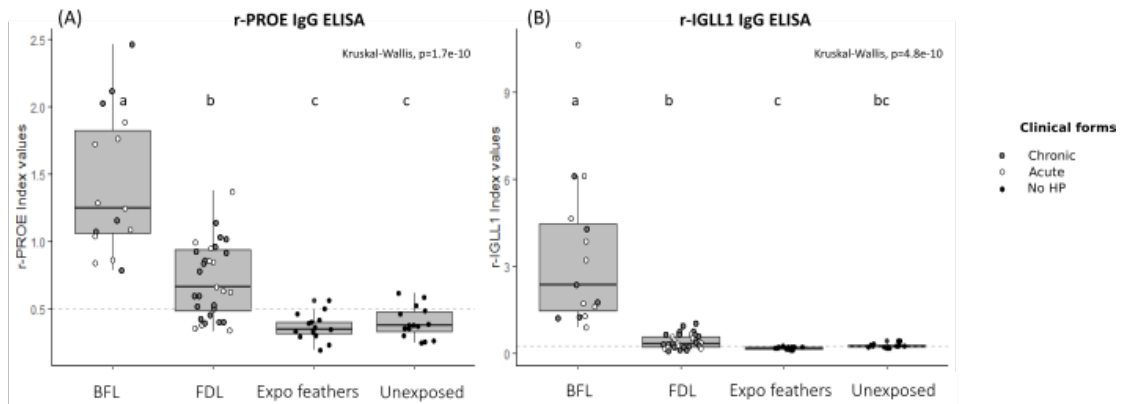

Figure 1 :

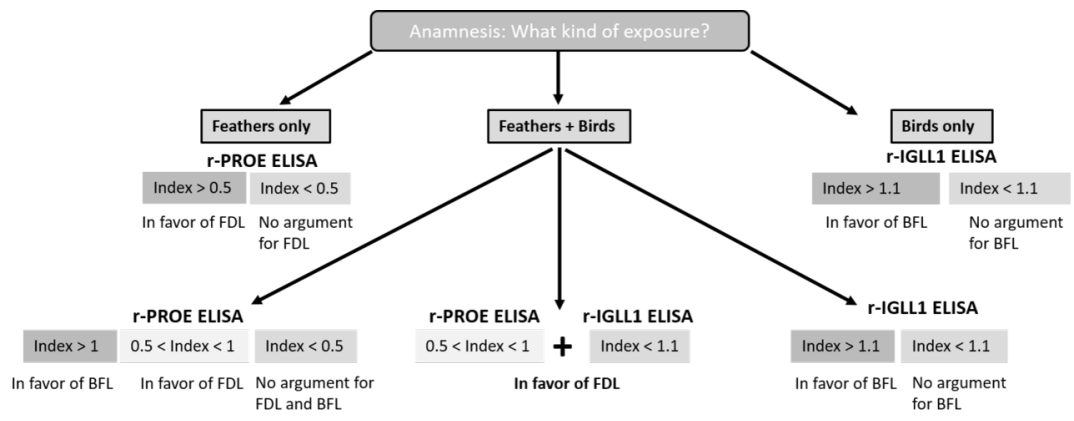

Figure 2 :

\section{APPENDICES}

\section{Material}

Comparison of the amino-acid sequences of the PROE and IGLL1 proteins of pigeons with their homologous proteins in geese and ducks.

Local alignments of the amino-acid sequences of pigeon PROE (XP_005514568) and IGLL1 (XP_005503921) proteins were performed against non-redundant (NR) protein sequences from a database of goose and duck taxids using the BLASTp tool. Identity (ID), similarity (SIM), and percentage coverage were used to compare the amino-acid sequences of the pigeon PROE and IGLL1 proteins with their homologous proteins in geese and ducks.

\section{Results}

\section{Comparison blast}

The PROE amino-acid sequences showed a minimum coverage of $73 \%$, with the percentage of identity ranging from 61 to $81 \%$ and the percentage of similarity from 68 to $88 \%$ (Table S1, supplemental data). The duck PROE protein has an amino acid sequence closer to that of pigeons than geese. The alignments of the IGLL1 amino-acid sequences showed a minimum coverage of $99 \%$, a percentage of identity ranging from 65 to $89 \%$, and a percentage of similarity from 77 to $89 \%$ (TableS1, supplemental data). The IGLL1 proteins of goose and duck showed highly conserved amino-acid sequences (Coverage: 100\%, ID, 81\%, SIM: 89\%). 


\section{Table S1.}

\begin{tabular}{llll}
\hline $\begin{array}{l}\text { Antigenic Pigeon proteins } \\
\text { (Accession Number) }\end{array}$ & $\begin{array}{l}\text { Alignment Pigeon / } \\
\text { Goose }\end{array}$ & $\begin{array}{l}\text { Alignment Pigeon / } \\
\text { Duck }\end{array}$ & $\begin{array}{l}\text { Alignment Goose/ } \\
\text { Duck }\end{array}$ \\
\hline $\begin{array}{l}\text { Pigeon PROE } \\
\text { (XP_005514568) }\end{array}$ & $\begin{array}{l}\text { Proproteinase E-like } \\
\text { (XP_013056116) ID: }\end{array}$ & $\begin{array}{l}\text { Proproteinase E-like } \\
\text { (XP_027303168) ID: }\end{array}$ & $\begin{array}{l}\text { BLASTp } \\
\text { (XP_013056116/ }\end{array}$ \\
& $\begin{array}{l}\text { 61\% SIM: } 68 \% \\
\text { Coverage: } 86 \%\end{array}$ & $\begin{array}{l}81 \% \text { SIM: } 88 \% \\
\text { Coverage: } 88 \%\end{array}$ & $\begin{array}{l}\text { XP_027303168) ID: } \\
73 \% \text { SIM: 74\% }\end{array}$ \\
& & & Coverage: $73 \%$ \\
Pigeon IGLL1 & Immunoglobulin light & Immunoglobulin & BLASTp \\
(XP_005503921) & chain V-J-C region & lambda light chain & (AMS75113/CAA57568) \\
& (AMS75113); 231 aa & (CAA57568); 230 aa & ID: $81 \%$ SIM: $89 \%$ \\
& ID: $66 \%$ SIM: $80 \%$ & ID: $65 \%$ SIM: $77 \%$ & Coverage: $100 \%$ \\
& Coverage: $99 \%$ & Coverage: $99 \%$ & \\
\hline
\end{tabular}

Table S1. Alignment of amino-acid (aa) sequences of pigeon, goose, and duck proteins.

Abbreviations: ID: identity, SIM: similarity. Alignments were conducted using BLASTp tools freely available athttps://blast.ncbi.nlm.nih.gov/Blast.cgi?PAGE=Proteins 